\title{
Analysis and measures for energy savings in operating theaters
}

\author{
Giuseppe Cannistraro $^{1}$, Mauro Cannistraro ${ }^{2}$, Antonio Galvagno ${ }^{1}$, GaetagnoTrovato $^{3}$ \\ ${ }^{1}$ Department of Engineering of Messina University of Messina \\ ${ }^{2}$ University of Ferrara, School of Architecture, Ferrara 40122, Italy \\ ${ }^{3}$ Architect, Freelancer, Milano 98121, Italy \\ E-mail: gcannistraro@unime.it
}

\begin{abstract}
In hospital, air conditioning and air treatment systems are of great importance both for functional and energetic point of view. In fact, these systems must guarantee the conditions of hygrothermal air quality and comfort for people (patients, staff, visitors), but also meet the operational requirements related to the medical activities in specific environments or departments. In particular, diagnosis and surgical activities request to ensure a high air quality conditions in order to ensure the appropriate environments of asepsis and hygiene [1-3]. The aim of this study is to evaluate the possible energy saving solutions to optimize and reduce energy demand [4-5] in the health facilities. Particular attention is focused to the operating theaters, which, because of the type of technological systems used, have a major impact on energy demand the entire healthcare facility.
\end{abstract}

Keywords: Air-conditioning Systems, Energy Saving, Thermal Comfort, Air Quality, Hospitals.

\section{ENERGY DEMAND IN HOSPITAL}

In hospitals, the energy demand of the different areas can be divided in form of thermal energy, cooling and electricity. The complexity of the energy system of each structure may be different from hospital to hospital as well as to the volume of manufactured. In fact, the energy demand is closely related to:

- health activities that take place in it;

- its geographical location;

- the structural type and adopted plant

The use of different type of energy sources is due to the implementation of different technology options and then to specific operating costs and levels of different issues.

In the graphs below (Figure 1 and 2) is shown the values and percentages of annual energy demand required for two different hospitals located in the northern of Italy, respectively: Zucchi Clinic (MB) and the City of Pavia Care Institute (PV) - Reference year 2012.

The energy demand for Heating, Ventilation and Air Conditioning (HVAC) is equal to $45 \%$ for the first structure and of $69 \%$ for the second structure analyzed.

It denotes in both cases, that this request always results in a higher percentage than all other requests and in the case of the care institute City of Pavia, the contribution percentage is higher of $50 \%$ higher.

Taking into consideration the same study, conducted for the Zucchi clinic and the City of Pavia health institution, also ensures that the demand for natural gas (methane gas) for technological uses is particularly relevant to the request for HVAC uses, and then for technological uses.

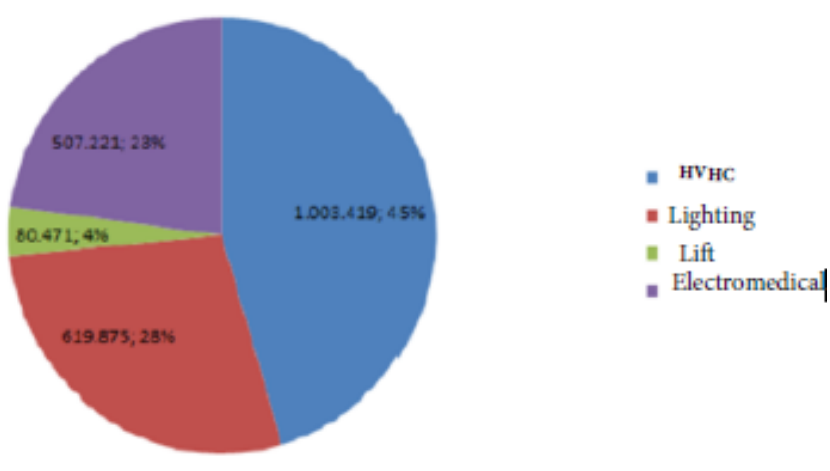

Figure 1. Electricity demand (Zucchi Clinic)

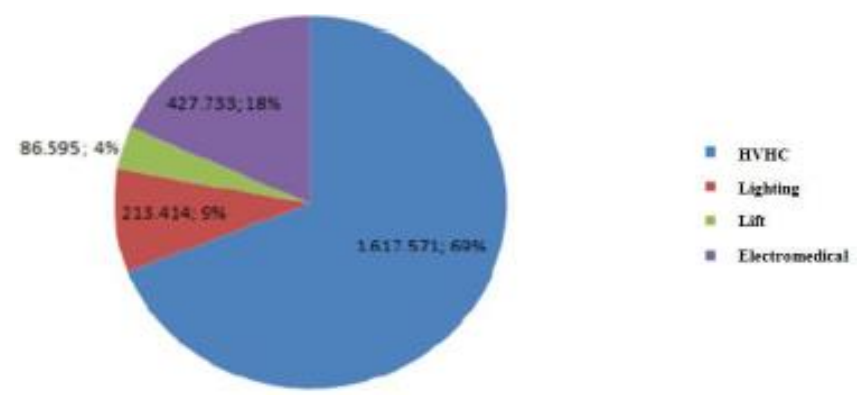

Figure 2. Electricity demand (Pavia Hospital)

In fact, the following charts (Figure 3 and 4) show that the demand for natural gas is higher in the winter months with a 
decreasing trend towards the period of the summer season. This trend shows how this power request is connected to the external environmental conditions, and then to an energy demand attributable to the use of systems for heating and air treatment in the winter period.

Among the utilities that affect significantly the demand for energy (heat and electricity) for HVAC uses, are included installations for air conditioning and air treatment within the rooms, and also the electricity demand of all auxiliary forming part of such systems.

This is due to the high external air volumes treated and the peculiar cycles and operating conditions in which they operate the operating rooms (temperature $20-22^{\circ} \mathrm{C}$, and minimum air flow $15 \mathrm{vol} . / \mathrm{h}$ of outside air).

Not by chance it is precisely in these areas that the greatest number of treatment plants with large external air flow is installed.

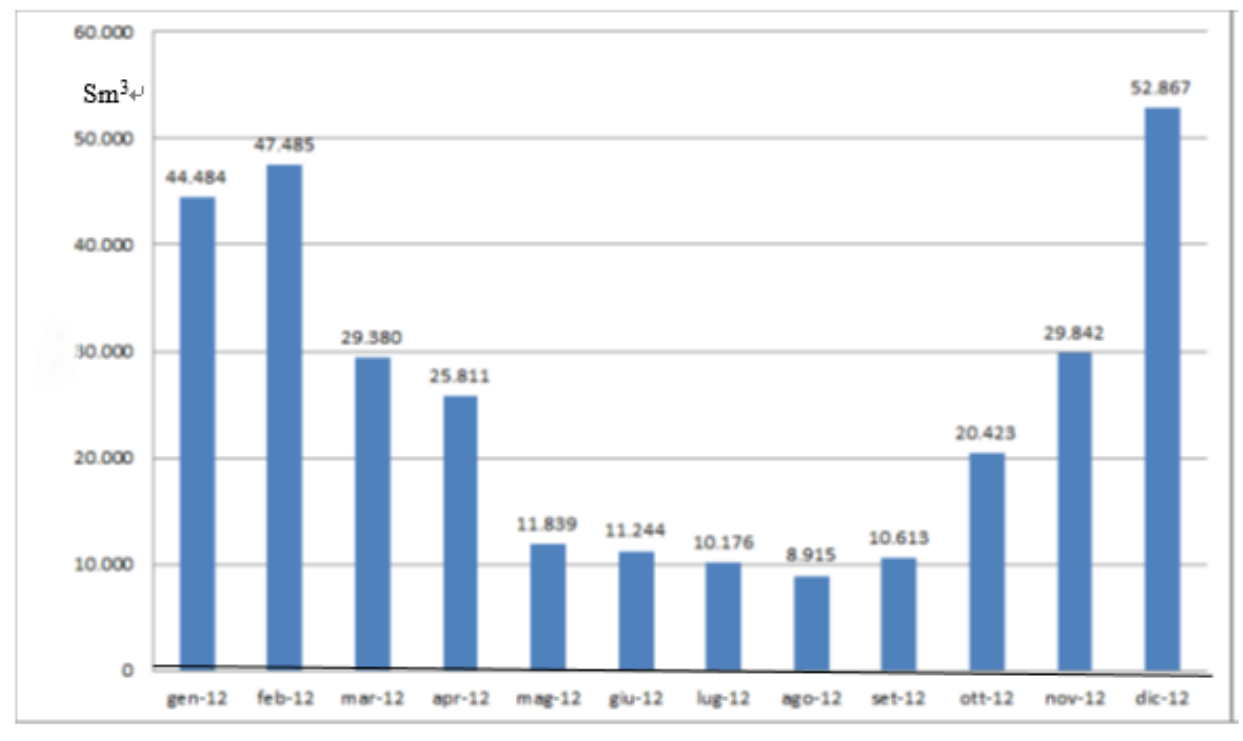

Figure 3. Natural gas inquiry (Zucchi Clinic)

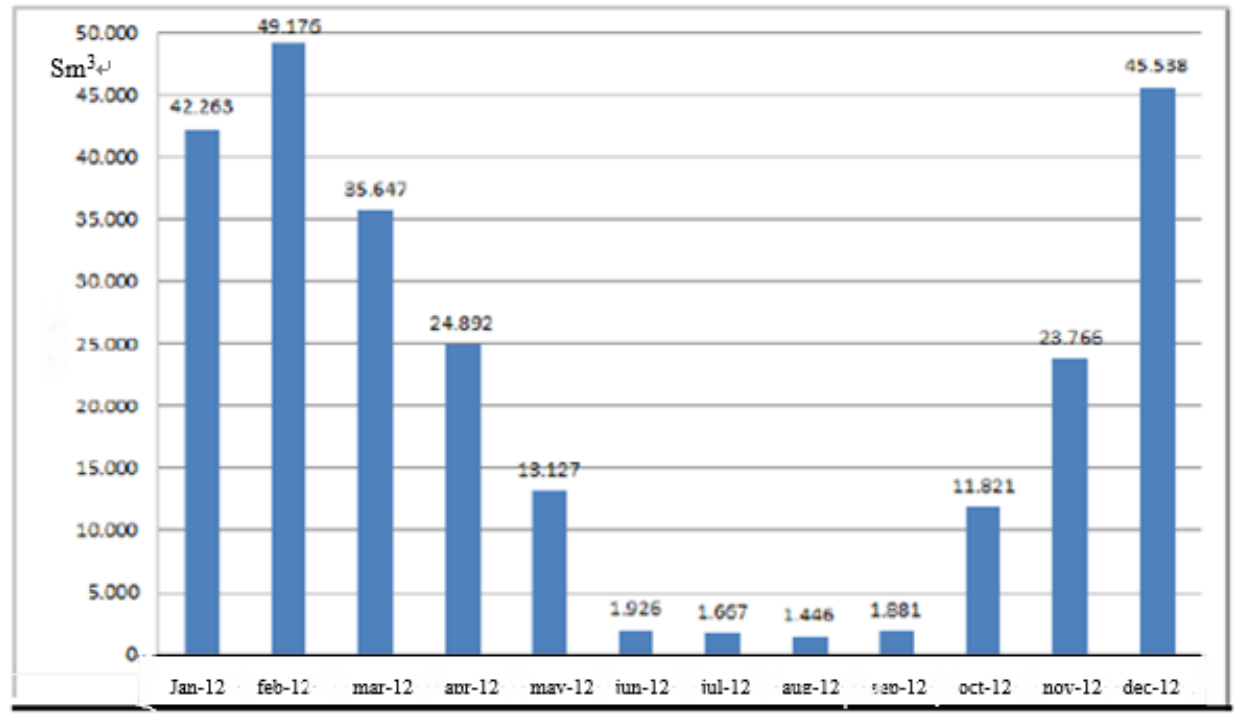

Figure 4. Natural gas inquiry (Pavia Hospital)

\section{REFERENCE STANDARDS FOR MECHANICAL SYSTEM PROJECT IN OPERATING ROOMS}

For completeness of speech, it is necessary refers to the reference standard in operating rooms design.

Laws and reference standards to be met in the design of mechanical systems (HVAC) of the operating theaters are shown below [6-10]:

- DPR 14 January 1997:"Act Approval of act of guidance and coordination to regions and autonomous provinces of Trento and Bolzano, in the field of structural, technological and organizational requirements for the' exercise of medical activities by public structures and private. "the above only sets the following parameters:

- Temperature winter and summer internal between 20 to $24{ }^{\circ} \mathrm{C}$

- The air humidity in summer and winter of 40-60\%

- Air time change (without external recirculation)

$15 \mathrm{Vol} . / \mathrm{h}$ (minimum volume)

- Air-Filtering $99.97 \%$

UNI 11425 Ventilation system and air conditioning controlled contamination (VCCC) for the operating theater - 
Design, installation, commissioning, qualification, management and maintenance, published on 22 September 2011.

The standard defines the requirements for VCCC system in the operating block service and suggests the environmental relative humidity requirements for the internal local constituents the above-mentioned operating block (Fig.1).

ISPESL "Guidelines for the definition of safety standards and environmental health departments of operators" 2009.

Regional Recommendations including in particular; in this regard, on Italian territory, many regions have exuded the applicable statutes lines, legislation whose validity of respect has exclusively regional character.

As complement the Italian technical legislation is customary reference to even the most important foreign standards, and in particular the German DIN 1946-4 "Ventilation and air conditioning - Part 4: VAC systems in buildings and rooms used in the health care sector" and the US ASHRAE 170-2013 "Ventilation of Health Care Facilities".

The pressure conditions prescribed by the latter for the various premises, in order to avoid possible contamination and leakage of air flows, are also normally employed in Italy.

ISO 14644: 2015 - Cleanrooms and associated controlled environments.

The different parts of the ISO 14644 standard defining the characteristics of the operating rooms, more generally of the clean room, relatively to the concentrations and sizes of airborne particles.

This rule is used for classification of the performance of an operating room in terms of air contamination level (ISO 5, ISO 7 , etc).

In the table of Figure 5, extracted by the UNI 11425: 2011, are shown the requirements of air ventilation systems, for the contaminants (VCCC) of the different areas of the surgical unit, in terms of temperature, relative humidity and filtration levels.

The table show it is possibility to performs, air recirculation for operating theaters inclused in the classes ISO5 and ISO7

\section{ENERGY SAVINGS STRATEGIES FOR OPERATING BLOCK}

In order to allow the reduction of the energy demand of air conditioning systems and air treatment in the operating rooms service the following different strategies can be pursued:

- Management/Procedural

- Projectual

- Optimization of energy production systems and energy recovery

The UNI 11425, in addition to defining the ones that are requirements relating to the control of contamination and the thermo-hygrometric control, poses a significant attention on the possibility of energy saving by identifying the following opportunities:

1. Recirculation of internal air

2. Load reduced operation during periods of non-activity of the operating theater.

3. Heat recovery from the exhaust air

From the point of view of energy saving, the UNI 11425 proposes a new scenario about the design choices and the operating procedures of the mechanical and technological systems in general.

The opportunities offered by the application of the above standard, allow an important energy saving in the energy management of the operating block and then consequently with positive repercussions for the entire energy expenditure of the hospital, since a high energy demand is attributable to the same operating block.

In continuation of the study, various energy saving strategies listed above will be analyzed individually.

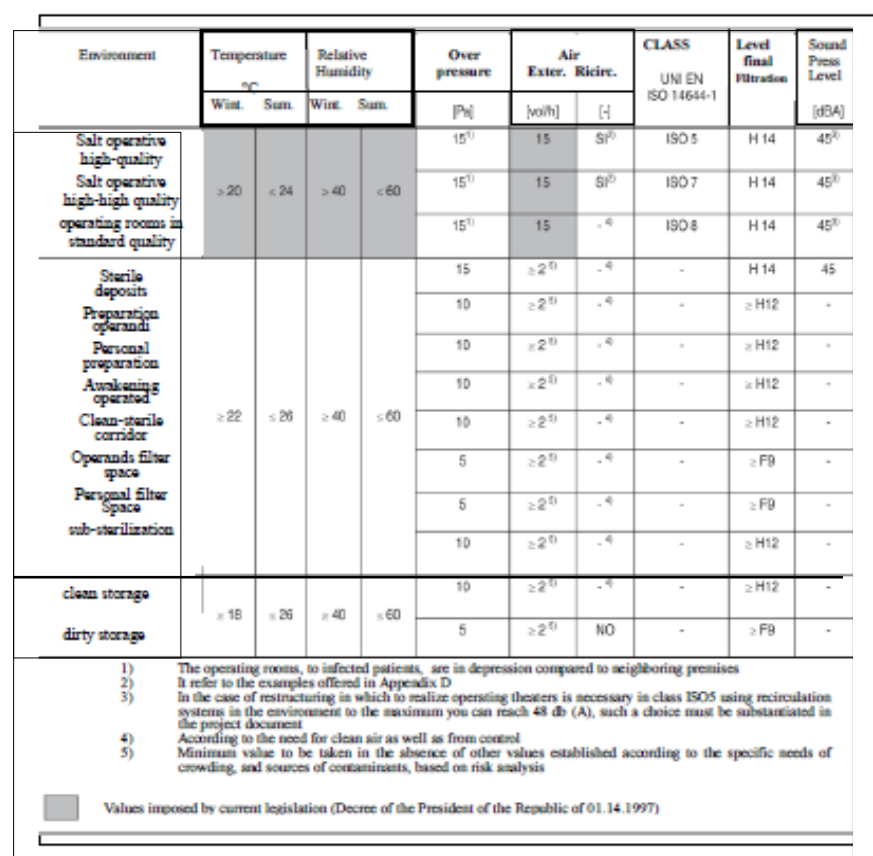

Figure 5. System requirements control ventilation air contaminants, operating

\section{NEW APPROACH OF THE UNI 11425 IN INDOOR AIR RECIRCULATION}

Besides air change by legislatively prescribe (Vol. $15 \mathrm{~min}$ $/ \mathrm{h}$ ), in general the VCCC plants require large air masses to ensure:

1. High levels of decontamination.

2. Stability of the unidirectional flow

3. Low temperature difference between input air and ambient air

In refer first point of the list, is more severe the contamination control of the operating room (so the lower the level of classification in accordance with ISO 14644: 2015) and more will be the time of air filtration.

In this regard, is intuitively that for reduced the air, by the contaminants, it is necessary to filter the air of the operating room a more number of times possible, so that for each cycle, the air is subjected at new filtering.

In the past, operator blocks were normally designed with VCCC installations in external all-air, without recirculation, with a flow of about $20 \div 25 \mathrm{Vol} . / \mathrm{h}$ of outside air, in order to ensure in each case, the high flow of air to meet the necessary requirements to reduce contamination.

According to the latest regulatory updates and according to the UNI 11425, the use of recirculated air in the individual operating rooms is permitted only by ensuring that the air is extracted and fed back into the same operating room.

Moreover, the same rule requires that the recirculated air is well mixed with the fresh air and which is in any case subject to the same stages of filtration to which the outside air is subjected. 
This a reduction of the external air flow (necessary for maintaining adequate the levels of indoor pollutants), involves a high reduction in energy demand for the treatment of the air hygrometric outside.

In the graphs below (Figure 6 and 7) is shown the result of an energy simulation to an all-air system with external service to an operating room of $60 \mathrm{~m}^{2}$ area located in a hospital near Milan. Where, for the attainment of adequate levels of air contamination, $25 \mathrm{vol} . / \mathrm{h}$ of air circulated from the treatment and air filtration system are required.

In the first condition is assumed a whole outside air condition in the second condition it is assumed that only 15 $\mathrm{vol} . / \mathrm{h}$ are related to outside air and the remaining $10 \mathrm{vol} . / \mathrm{h}$ of air are recirculated.

The operating rooms are in depression compared to neighboring premises.

The following Table 1 and Table 2, show the summary of monthly results of the Thermal Energy demand for air treatment in the processes surgery.

Table 1. Thermal Energy demand air treatment surgery

\begin{tabular}{ccc}
\hline & All air External & Partial recirculation \\
\hline & $\begin{array}{c}\text { Thermal Energy } \\
k W h\end{array}$ & $\begin{array}{c}\text { Thermal Energy } \\
k W h\end{array}$ \\
Jan & 51383 & 21581 \\
Feb & 43533 & 18284 \\
Mar & 21410 & 8992 \\
Apr & 6581 & 2764 \\
Oct & 14273 & 5995 \\
Nov & 39251 & 16485 \\
Dec & 44246 & 18584 \\
Tot & $\underline{220677}$ & $\underline{92684}$ \\
\hline
\end{tabular}

Table 2. Energy demand for cooling air treatment surgery

\begin{tabular}{ccc}
\hline & All air External & $\begin{array}{c}\text { Partial } \\
\text { recirculation }\end{array}$ \\
\hline Cooling Energy \\
kWh & $\begin{array}{c}\text { Cooling Energy } \\
k W h\end{array}$ \\
Jun & 14989,104 & 8993 \\
Jul & 18736,38 & 11242 \\
Aug & 24942,06 & 14965 \\
Sep & 22316,58 & 13390 \\
Tot & 18736,38 & 11242 \\
\hline
\end{tabular}

Current legislation imposes the values imposed by (Decree of the President of the Republic of 01.14.1997)

It shows as in terms of energy savings, during the winter period it is possible to achieve a saving of heat energy equal to $42 \%$, while during the summer period, the saving of cooling energy achievable is $60 \%$.

In the results following, they are not shown the values and comparison relatively to the humidification and dehumidification of the air as well as the post-heating. However, even for such type of treatment the energy saving is tangible.

The cooling systems in hospitals during summer season are faced with increases in thermal loads, due to asymmetry of the mean radiant temperature, which is often aggravated by orientation of the structure [11-13].

The development and use of new technologies, "e-sensing", for monitoring in the hospital fields, [14-16], in urban settings: for the detection of pollutants main [17-21], and in the ambient of museums, [22-25], allows you to take into account the synergies between all monitoring parameters and the consequences of the exceeding the of parameters of risk.

In the field of eco-friendly air conditioning systems and in line with the new energy-saving policies, significant progress has been achieved and are desirable in the near future for these applications [26-30].

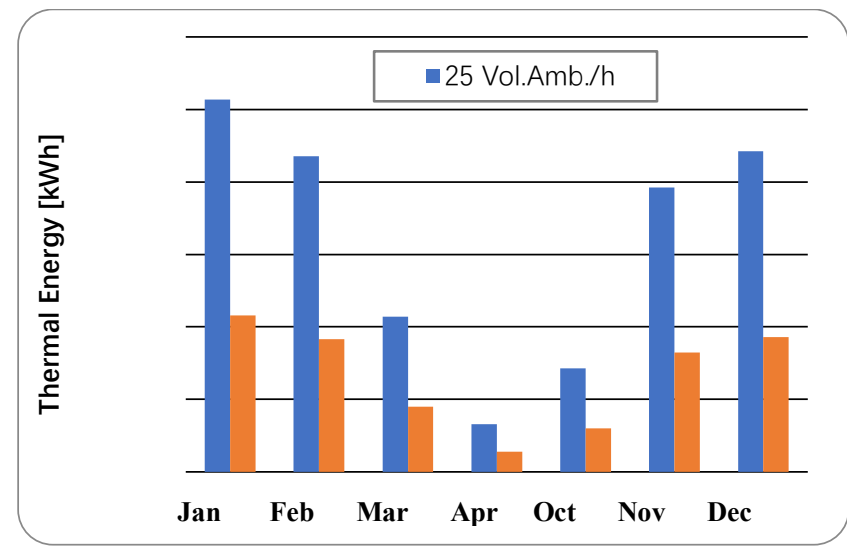

Figure 6. Comparison between external all-air system and partial recirculation in winter season

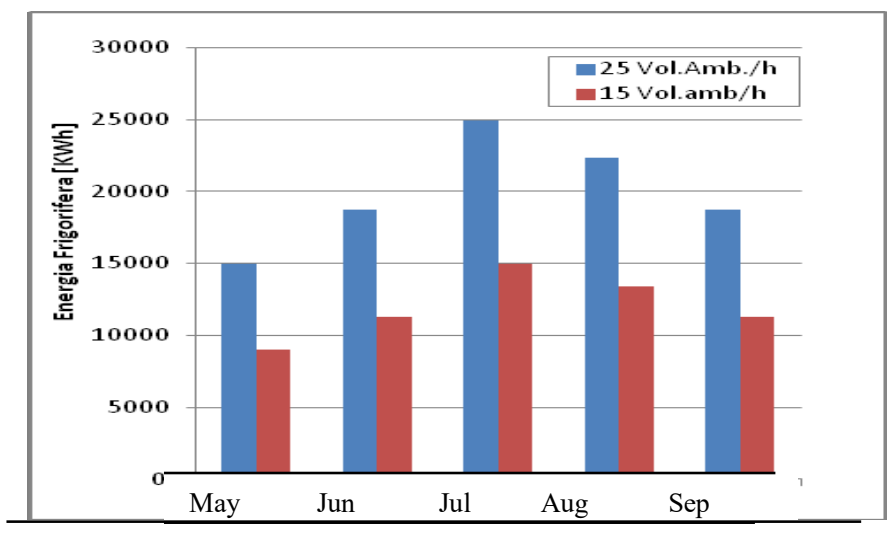

Figure 7. Comparison between external all-air system and partial recirculation in summer season

\section{RECOVERY OF HEAT, EXHAUST AIR}

With regard to heat recovery, the UNI 11425 refers to the possibility of heat recovery. In particular, it reports in its text that: "In particular, the heat recovery systems must be selected and installed in such a way as to ensure the absence of infiltrations or the transmission of contaminants between the exhaust air flow and the fresh air flow"

Since it is not subject to cross contamination phenomena, the frequently used system relative to the heat recovery from the air expelled into the operating room is constituted by a hydronic system. It consists of two independent batteries of heat exchanger, respectively installed on the exhaust air duct and on the inlet air duct, and of a hydronic circuit that allows the transfer of thermal energy between the two sections, respectively (expulsion and primary air entry) (Fig.8).

Such energy recovery system is characterized by:

- Sensible heat recovery (it is not possible to make recovery of latent heat)

- Considerable values of sunshine efficiency in high temperature difference condition between the value of the entry and ejection temperature. 
- The flow values of air injection and expulsion must be next to each other.

- High load loss in areaulica distribution circuits (220-300 Pa), and then consequently high electric power demand of the fans.

- It is not subject to possible cross-contamination phenomena because the supply air flows and expulsion air, are not physically in contact with each other.

From an energy point of view, such some systems are characterized by a reduced value of energy efficiency, as the values of the temperature differences are particularly reduced.

So, for most of the time it is appropriate that the heat recovery system is escluse, that in order to avoid an increased demand for electrical energy on the part of fans.

Therefore Is evident, the importance of the energy recovery from by the exhaust for air flow treated in the plant.

Hence the classical scheme described above, consisting of an air/water battery on the expelled air, a hydraulic circuit served by a pump, and from another air/water battery inside the unit, is considered unsatisfactory.

Therefore, in order to optimize the energy recovery, it is possible to employ a reversible water/water type heat pump, ideally placed between the exhaust air ejection section and the input section. In this case, two separate circuits are realized in order to hydraulically connect the primary circuit of the heat pump and the secondary one, always of the heat pump with the air expulsion section.

During the winter (Fig. 9), the heat pump extracts heat from the air that come out from the building, characterized by a constant value of temperature (around $22{ }^{\circ} \mathrm{C}$ ), and transfers this energy to the renewal air flow which has a variable temperature (eg. Milan, from $-5^{\circ} \mathrm{C}$ to $20^{\circ} \mathrm{C}$ ), therefore with an average value of temperature of $7^{\circ} \mathrm{C}$.

Exchanging heat by a source at $22{ }^{\circ} \mathrm{C}$, the heat pump can work with a COP value greater than 4 , therefore it is generally more convenient compared it to the production by a traditional generator source.

In this way, the system is so designed to be substantially independent of the outside air temperature value.

Assuming an EERPDC-REC (Energy Efficiency Ratio) value of approximately 4 for the heat pump in the cooling energy production, it is necessary to make a consideration on the convenience to use this type of recovery or a new reconfiguration plant such as to maximize the exploitation of the heat recovery system. In this case, during the summer season the heat pump should be used in the opposite way.

However, in order to verify the energy and economic convenience, it is necessary to compare the EER value of the heat pump with that of the existing centralized system.

In this case, two different scenarios can be evaluated:

a) If the value of EER of the heat recovery pump system is greater than the one of the centralized system EERcent (considering a same energy request for auxiliaries), it is convenient to use the recovery heat pump system. In this condition, the plant configuration is shown in Figure 9.

b) In the case in which the EERcent is greater than the one of the heat recovery pump system (e.g. using a condensate centrifugal chillers water by evaporative towers $-\mathrm{EER}=6$ ), there is no convenience in the cooling energy production at the expense of production by the central system. Given that the efficiency of production of thermal energy from said heat pump is greater than conventional systems employing conventional combustibility, it is considered more appropriate to use a heat of the " type polyvalent pump "for the production of thermal energy in order to meet the demand for energy of the post-heating system.

The cooling energy obtainable, simultaneously with the production of thermal energy, thanks to the use of a polyvalent heat pump is used for pre-cooling the renewal air thanks to a simple hydronic circuit and so almost free. In this condition, the plant configuration is shown in (Fig. 10)

From the considerations made, it is clear that it is not immediate evaluate and estimate of the energy savings, obtained with the heat recovery system.

It also necessary to consider, in the energy balance, the demand for energy arising from the auxiliary systems (pumps and fans) consequently to the different operating conditions or in the presence or absence of a heat recovery system.

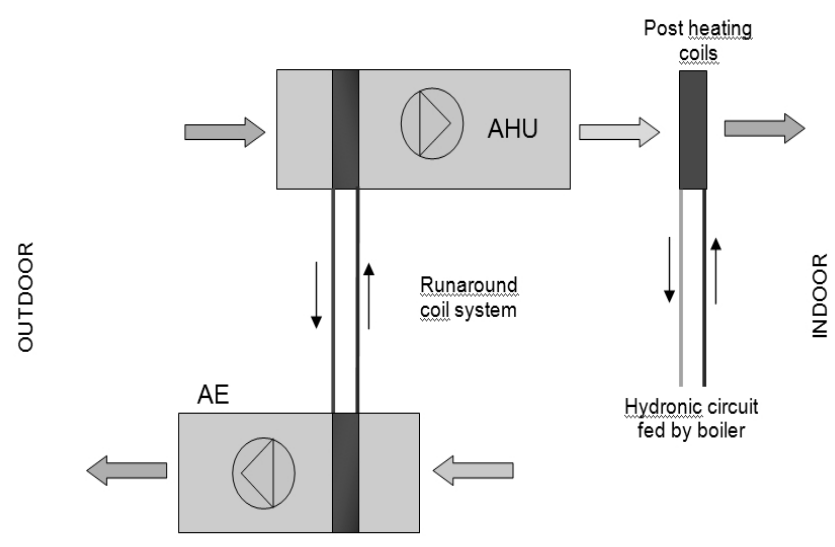

Figure 8. Recovery system using decoupled system batteries

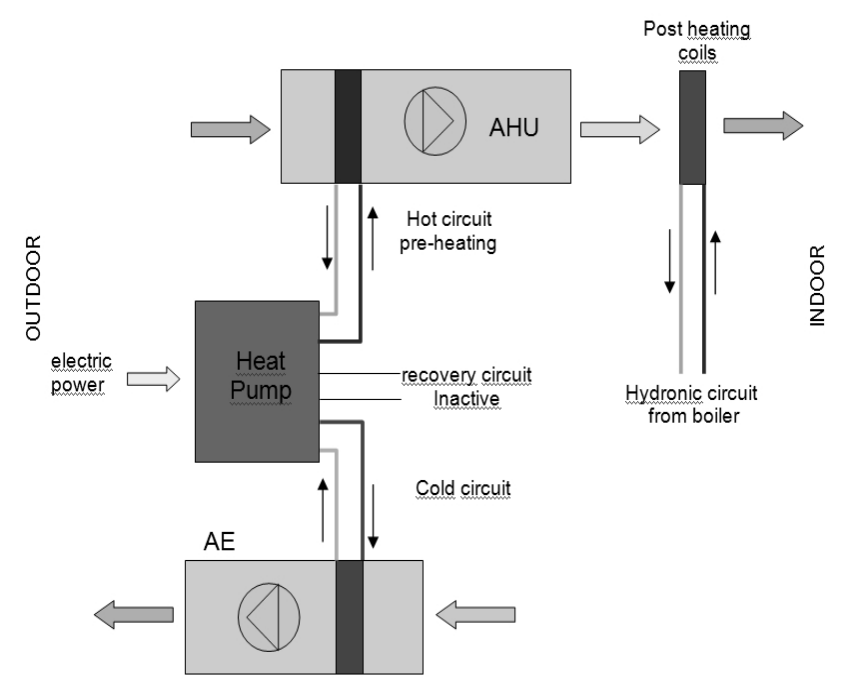

Figure 9. Active recovery system-winter

\section{LOAD REDUCTION DURING IN PERIODS OF NON ACTIVITY}

According to the UNI 11425, for the purposes of reducing energy consumption in the condition of non-operation of the operating block, is allowed to reduce the flow of fresh air to the minimum values.

Furthermore, is necessary maintaining the premises in overpressure, compared to other environments, and to hold 
them cleans by to possible contamination releases from objects present or from chemical contamination.

In this respect, also the 2009 ISPESL Guidelines allow to reduce the flow of external air towards the inactive operating rooms, at a minimum of $6 \mathrm{Vol} . / \mathrm{h}$.

In a similar way, as discussed in the previous chapter, the reduction of the external air flow significantly reduces the energy demand during periods in which operating rooms are not in activity.

The operating conditions given by the UNI 11425, compared to the ISPESL Guideline 2009, allow a greater energy saving, and are the necessary to ensure the overpressure is the optimal one.

However, such air exchange value depends on the type and constitution of the operating room. In any case must be guaranteed, even during the non-employment of the operating room, that any polluting substance, released into the internal environment, is removed thanks to the treatment system of air.

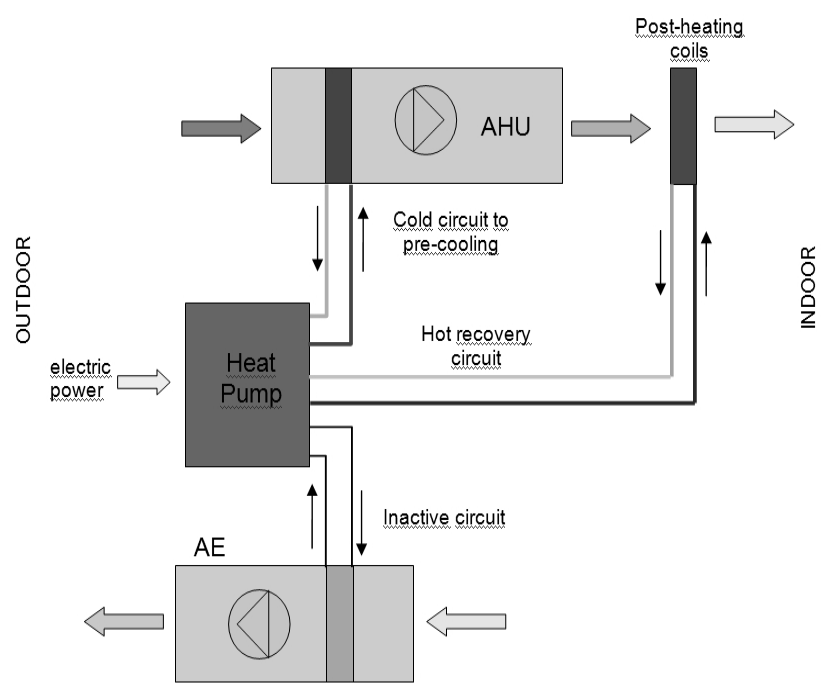

Figure 10. Active recovery system-summer

\section{CONCLUSIONS}

The energy for Heating, Ventilation and Air Conditioning required in the hospitals service is particularly relevant.

On valuations of their contribution are influenced by the nature of the operating blocks area for the significant hourly energy demand for the treatment of the air renewable

In order to reduce the energy demand for the air treatment of the surgical unit, the application of the standard UNI 11425 allows a high energy savings as a result of both design and management approach.

Among all the rules, this rule clarifies the concept that the entire flow of the air introduced inside the operating room not it must be exclusively external, but it is also allowed the air recirculation.

And hence is a prejudice, the assumption, that is required, for the satisfaction of some requirements, only the air renovable external.

In this regard, a heat recovery system of thermodynamic type, using a water/water heat pumps, are particularly advantageous and allow to significantly reduce the energy requirements for the air treatment both in the winter than in the summer period.
The heat recovery from the exhaust air plays a main role in order to allow a high energy saving.

With regard to the heat recovery it is considered necessary that any design choice intended for an energy-saving intervention must be supported by energy evaluation accurate.

\section{REFERENCES}

[1] UNI 11425 (2011). Surgery operating theatre, ventilation and air-conditioning system for contamination control (VCCC) - Design, construction, commissioning, qualification, management and maintenance, Italy.

[2] ISPESL (2009). Dipartimento Igiene del Lavoro, Linee guida per la definizione degli standard di sicurezza e di igiene ambientale dei reparti operatori, Italy. http://www.ispesl.it/

[3] Balocco C., Petrone G., Cammarata G. (2015). Numerical investigation of different airflow schemes in a real operating theatre, Biomedical Science and Engineering, Vol. 8, pp. 73-89.

[4] Balocco C., Petrone G., Cammarata G. (2012). Assessing the effects of sliding doors on an operating theatre climate. building simulation, An International Journal, Vol. 5, pp. 73-83.

[5] Balocco C., Petrone G., Cammarata G. (2013). Numerical multi-physical approach for the assessment of coupled heat and moisture transfer combined with people movements in historical buildings, Building Simulation: An International Journal, Vol. 7, No. 3, pp. 289-303. DOI 10.1007/s12273-013-0146-3

[6] Balocco C., Petrone G., Cammarata G., Vitali P., Albertini R., Pasquarella C. (2014). Indoor air quality in a real operating theatre under effective use conditions, Biomedical Science and Engineering, Vol. 7, pp. 866883.

[7] UNI EN ISO 14644-1 2006 (2006). Classification of Air Cleanliness, Clean rooms and associated controlled environments.

[8] ANSI/ASHRAE-170 (2008). Ventilation of health care facilities, ASHRAE Standards Committee, the ASHRAE Board of Directors, and the American National Standards Institute, USA.

[9] UNI EN ISO 14644-3 2006 (2006) Clean rooms and Associated Controlled Environments-Part 3: Test

[10] UNI EN ISO 7726-Gen. (1998). Ergonomics of thermal environments - Measuring instruments for physical quantities.

[11] Cannistraro G., Cannistraro M., Restivo R. (2015). Some observations on the radiative exchanges influence on thermal comfort in rectangular open-space environments, IJH\&T, Vol. 33, pp. 79-84. DOI: 10.18280/ijht.330213

[12] Cannistraro G., Cannistraro M., Restivo R. (2015). The local media radiant temperature for the calculation of comfort in areas characterized by radiant surfaces, IJH\&T, Vol. 33, pp. 115-122. DOI: 10.18280/ijht.330116

[13] Olesen B.W. (1984). Howmany sites are necessary to estimate a mean skin temperature, Thermal Physiology, J.R.S. Hales, New York: Raven Press pp. 34-38.

[14] Cannistraro G., Cannistraro M. (2016). Hypothermia risk, monitoring and environment control in operating rooms, $I J H \& T$, Vol. 34, No. 2, pp. 165-171. DOI: $10.1007 / \mathrm{s} 12273-010-0017-0$ 
[15] Cannistraro M., Leonardi S.G., Aloisio D., Patti E., Pace C., Khalaf W., Donato N., Neri G. (2013). Development of electronic-nose technologies for biomedical applications, Intern. Congress XVII Annual Conference AISEM, Brescia.

[16] Cannistraro M., Lorenzini E. (2016). The applications of the new technologies "E-sensing" in hospitals, IJH\&T Vol. 34, No. 4, pp. 551-557. DOI: 10.18280/ijht.34040

[17] Salata F., Golasi I., Petitti D., de Lieto Vollaro E., Coppi M., de Lieto Vollaro A. (2017). Relating microclimate, human thermal comfort and health during heat waves: An analysis of heat island mitigation strategies through a case study in an urban outdoor environment, Sustainable Cities and Society, Vol. 30, pp. 79-96. DOI: 10.1016/j.scs.2017.01.006

[18] Cannistraro G., Cannistraro A., Cannistraro M., Galvagno A., Trovato G. (2016). Analysis of the air pollution in the urban center of four Sicilian cities, IJH\&T, Vol. 34, No. 2, pp. 219-225. DOI: 10.18280/ijht.34S205

[19] Cannistraro G., Cannistraro M., Cannistraro A. (2016). Evaluation of the sound emissions and climate acoustic in proximity of one railway station, $I J H \& T$, Vol. 34, No. 2, pp. 589-596. DOI: 10.18280/ijht.34S255

[20] Marino C., Nucara A., Pietrafesa M. (2015). Mapping of the indoor comfort conditions considering the effect of solar radiation, Solar Energy. Vol. 113, pp. 63-77. DOI: 10.1016/j.solener

[21] Marino C., Nucara A., Pietrafesa M. (2017). Thermal comfort in indoor environment: Effect of the solar radiation on the radiant temperature asymmetry, Solar Energy. Vol. 144, pp. 295-309. DOI: 10.1016/j.solener

[22] Cardinale N., Stefanizzi P., Rospi G., Augenti V. (2010). Thermal performance of a mobile home with light envelope, Bulding Simulation, Vol. 3, pp. 331-338. DOI: 10.1007/s12273-010-0017-0

[23] Cannistraro M., Cannistraro G., Piccolo A., Restivo R. (2013). Potential and limits of oxidative photocatalyses and possible applications in the field of cultural heritage, Advanced Materials Research, Vol. 787, pp. 111-117.

[24] Cannistraro G., Cannistraro M., Restivo R. (2013). Messina's historical buildings after the earthquake of 1908: Energy and environmental analysis through a global screening methodology, $I J H \& T$, Vol. 31, No. 2, pp. 155-158. DOI: 10.18280/ijht.310221

[25] Cardinale T., Rospi G., Cardinale N. (2014). The influence of indoor microclimate on thermal comfort and conservation of artworks: The case study of the Cathedral of Matera (South Italy), Energy Procedia, Vol. 59, pp. 425-432, DOI: 10.1016/j.egypro.2014.10.398

[26] Cannistraro G., Cannistraro M., Galvagno A., Trovato G. (2016). Reduced the demand of energy cooling in the CED, centers of processing data, with use of free-cooling systems, IJH\&T, Vol. 34, No. 3, pp. 489-502. DOI: 10.18280/ijht.340321

[27] Salata F., Alippi C., Tarsitano A., Golasi I., Coppi M. (2015). A first approach to natural thermoventilation of residential buildings through ventilation chimneys supplied by solar ponds, Sustainability (Switzerland), Vol. 7, No. 7. DOI: 10.3390/su7079649

[28] Cannistraro G., Cannistraro M., Galvagno A., Trovato G. (2015). Evaluation of the convenience of a citizen service district heating for residential use. A new scenario introduced by high efficiency energy system, IJH\&T, Vol. 33, No. 4, pp. 167-172. DOI: 10.18280/ijht.330421

[29] Cannistraro G., Cannistraro M., Galvagno A., Trovato G. (2016). Evaluation technical and economic the integrations of co-trigeneration systems in the dairy industry, IJH\&T, Vol. 34, Sp. 2, pp. 332-336. DOI: 10.18280/ijht.34S220

[30] Piccolo A., Siclari R., Rando F., Cannistraro M. (2017). Comparative performance of thermoacoustic heat exchangers with different pore geometries in oscillatory flow. Implementation of Experimental Techniques, Applied Science, Vol. 7, p. 784. DOI: $\underline{10.3390 / a p p 7080784}$ 